\title{
Short stature-related single-nucleotide polymorphism (SNP) activates endothelial repair activity in elderly Japanese
}

\author{
Yuji Shimizu ${ }^{1,2^{*}}$ D, Hirotomo Yamanashi ${ }^{3}$, Yuko Noguchi ${ }^{1}$, Jun Koyamatsu4, Mako Nagayoshi ${ }^{4}$, Kairi Kiyoura$^{1}$,
} Shoichi Fukui ${ }^{1}$, Mami Tamai ${ }^{5}$, Shin-Ya Kawashiri ${ }^{1}$, Kazuhiko Arima ${ }^{6}$ and Takahiro Maeda ${ }^{1,3,4}$

\begin{abstract}
Background: Hypertension and atherosclerosis are bidirectionally related, while platelet count could serve as an indicator of endothelial repair. Therefore, high platelet counts could be associated with hypertension by indicating more intense endothelial repair activity. Furthermore, short stature has been shown to constitute a risk of atherosclerosis. Since inflammation-related single-nucleotide polymorphism (SNP (rs3782886)) is reportedly associated with myocardial infarction and short stature, rs3782886 could be associated with a high platelet count and thus more intense endothelial repair activity.
\end{abstract}

Methods: We conducted a cross-sectional study of 988 elderly Japanese who participated in a general health check-up. Short stature was defined as a height of at or under the 25th percentile of the study population, and high platelet count as the highest tertiles of the platelet levels.

Results: High platelet counts were found to be independently and positively associated with hypertension while rs3782886 was independently associated with high platelet levels and short stature. The classical cardiovascular risk factor-adjusted odds ratio (OR) and 95\% confidence interval (Cl) of high platelet count for hypertension was $1.34(1.02,1.77)$. With non-minor homo of the rs3782886 as the reference group, the adjusted OR and $95 \% \mathrm{Cl}$ for high platelet count and short stature of minor home were $2.40(1.30,4.42)$ and $2.21(1.16$, 4.21), respectively.

Conclusion: SNP (rs3782886) was shown to be associated with high platelet count and short stature. This result partly explains how a genetic factor can influence the impact of height on endothelial repair.

Keywords: Height, Hypertension, Platelets, rs3782886, SNP

\section{Background}

Hypertension is known as a major risk factor of stroke for Japanese [1] while short stature is well known as a Japanese characteristic. Furthermore, short stature has been reported to have an independent association with hypertension [2], carotid atherosclerosis [3], and incidence of stroke [4]. However, previous studies of ours indicate that the presence of carotid atherosclerosis

\footnotetext{
* Correspondence: shimizuyuji@nagasaki-u.ac.jp

${ }^{1}$ Department of Community Medicine, Nagasaki University Graduate School of Biomedical Sciences, Nagasaki-shi, Sakamoto 1-12-4, Nagasaki 852-8523, Japan

${ }^{2}$ Department of Cardiovascular Disease Prevention, Osaka Center for Cancer and Cardiovascular Disease Prevention, Osaka, Japan

Full list of author information is available at the end of the article
}

cannot explain the risk of stroke associated with short stature $[3,4]$.

Recently, hematopoietic activity has been revealed to be closely associated with vascular maintenance activity (endothelial repair activity [5-8]). Short stature has been shown to be associated with lower capacity for hematopoietic activity $[9,10]$ and with anemia $[11]$ possibly due to the fact that height indicates the absolute volume of total bone marrow. Higher capacity for hematopoietic activity (high hemoglobin level) has been found to be positively associated with atherosclerosis $[6$, 7] and hypertension [8, 12].

(c) The Author(s). 2019 Open Access This article is distributed under the terms of the Creative Commons Attribution 4.0 International License (http://creativecommons.org/licenses/by/4.0/), which permits unrestricted use, distribution, and reproduction in any medium, provided you give appropriate credit to the original author(s) and the source, provide a link to the Creative Commons license, and indicate if changes were made. The Creative Commons Public Domain Dedication waiver (http://creativecommons.org/publicdomain/zero/1.0/) applies to the data made available in this article, unless otherwise stated. 
Those studies raise issues emerging from paradoxical findings for short stature as a risk for anemia, hypertension, carotid atherosclerosis, and incidence of stroke.

Since atherosclerosis results from aggressive endothelial repair, the findings of these studies indicate that the risk of stroke in people with short stature might be associated with low endothelial repair activity (low hematopoietic activity).

Single-nucleotide polymorphism (SNP) (rs3782886) in breast cancer suppressor BRCA1-related associated protein (BRAP) is reportedly associated with risk of myocardial infarction [13], while SNP (rs3782886) is also found to be associated with short stature in a previous study by us [14]. Another study reported that BRAP activates inflammatory cascades and increases the risk of carotid atherosclerosis [15] but is not associated with risk of stroke [16]. Although an SNP (rs3782886) could be associated with carotid atherosclerosis, these studies indicate that it might also have a beneficial effect on stroke prevention by inducing endothelial repair in participants with short stature; otherwise, these participants would have high risks of hypertension [2], carotid atherosclerosis [3], and stroke [4].

Furthermore, platelet is known to contribute to endothelial repair [17]. We previously showed that platelet levels were positively associated with hypertension [18] and that platelet count could serve as an indicator of vascular repair (endothelial repair and developing atherosclerosis) [19]. Since the association between hypertension and atherosclerosis (increased arterial stiffness) is bidirectional [20-22], high platelet levels, which are associated with hypertension, can be expected to reflect a higher activity of endothelial repair.

Since height is inversely associated with platelet count in elderly men [23], clarification of the relationship of SNP (rs3782886) with short stature and high platelet counts, which are in turn associated with hypertension, should provide us with an efficient tool to clarify the underlying mechanism of the effect of height on endothelial repair.

We therefore hypothesized that hypertension is positively associated with a high platelet count, thus indicating active endothelial repair. Moreover, that SNP (rs3782886) is also associated with a high platelet count and short stature since it plays an important role in the activation of endothelial repair in participants with short stature.

To elucidate those associations, we conducted a cross-sectional study of 988 elderly Japanese participants aged 60-89 years who participated in a general health check-up in 2014 and 2015.

\section{Methods}

\section{Study population}

The total number of residents of Goto City aged 60-89 in 2015 was 16,176, based on an estimate by the
National Institute of Population and Social Security Research in March 2013 [24].

The study population comprised 992 Japanese elderly residents aged 60-89 years from the rural communities of the Goto Islands in western Japan, who underwent annual medical check-ups in 2014 and 2015 as recommended by the Japanese government.

Participants without SNP data $(n=3)$ and without blood pressure data $(n=1)$ were excluded, leaving 988 participants with a mean age of 72.6 years (standard deviation (SD), 7.3; range, 60-89) enrolled in the study.

\section{Data collection and laboratory measurements}

Trained interviewers obtained information on medical history (lifestyle habit). Body weight and height were measured with an automatic body composition analyzer (BF-220; Tanita, Tokyo, Japan), and body mass index (BMI; $\mathrm{kg} / \mathrm{m}^{2}$ ) was calculated. Systolic and diastolic blood pressure were recorded at rest. Blood samples were collected in an EDTA-2 K tube, a siliconized tube, and sodium fluoride tube. The number of platelets in samples from the EDTA-2 K tube was measured with an automated procedure at SRL, Inc. (Tokyo, Japan). Triglycerides (TG) and serum creatinine were measured enzymatically, while HDL cholesterol (HDLc) was measured with a direct method and hemoglobin A1c (HbA1c) with the latex coagulation method. Genomic DNA was extracted from $2 \mathrm{ml}$ of whole peripheral blood by means of the Gene Prep Star NA-480 (Kurabo Industries Ltd., Osaka, Japan) and typed for SNP rs3782886 (BRAP on chromosome 12q24.12) by using the HybProbe method with LightCycler 480 (Roche Diagnostics, Basel, Switzerland). Hypertension was defined as systolic blood pressure $\geq 140 \mathrm{mmHg}$ and/or diastolic blood pressure $\geq 90 \mathrm{mmHg}$. A high platelet level was defined as the highest tertile $\left(\geq 22.0 \times 10^{4} / \mu \mathrm{L}\right.$ for men and $\geq 24.2 \times 10^{4} / \mu \mathrm{L}$ for women) and short stature as a height level at or under the 25th percentile of the study population $(<158.4 \mathrm{~cm}$ for men and $<146.4 \mathrm{~cm}$ for women) as in a previous study by us [3, 14].

\section{Statistical analysis}

Characteristics of the study population stratified by platelet level and SNP (rs3782886) genotype were expressed as mean \pm standard deviation. A trend test was performed with analysis of variance (ANOVA) for continuous values, and chi-squared test was used for determining proportions.

Logistic regression models were also used to calculate odds ratios (ORs) and 95\% confidence intervals (CIs) in order to determine the influence of platelet level on hypertension. In addition, ORs and 95\% CIs were calculated by using a logistic regression model to determine 
the influence of SNP (rs3782886) on high platelet counts, hypertension, and short stature.

Adjustments for confounding factors were made by using two models. In the first model (model 1), adjustment was made only for age and sex. Alcohol consumption has been shown to be positively associated with height in previous studies $[3,4,25]$, and white blood cell count to be a factor that is influenced by smoking status [26] while height is inversely associated with high white blood cell count [25]. BMI could be positively associated with endothelial repair (CD34-positive cell count) $[8,18$, 27-29] while height is positively associated with CD34-positive cell count in participants with systolic hypertension [30]. Another study reported the identification of a primary association between a genetically determined short stature and an increased risk of cardiovascular disease which may be partly explained by the association between short stature and adverse lipid profile [31]. In one of our studies, we reported that the activity of endothelial repair (CD34-positive cells) might influence the association between blood pressure and TG [29] and HDLc [28]. HbA1c has also been found to be associated with atherosclerosis [32, 33]. All these factors are well-known classical cardiovascular risk factors. Furthermore, renal function is reportedly associated with SNP (rs3782886) [34], endothelial repair (CD34-positive cells) [35], anemia [36], and incidence of stroke [37]. We therefore added serum creatinine as a confounding factor to the aforementioned classical cardiovascular risk factors for the present analysis. Therefore, the second model (model 2) included other, possibly confounding, factors, namely, BMI $\left(\mathrm{kg} / \mathrm{m}^{2}\right.$ ), (systolic blood pressure (mmHg), which was not applicable to the analysis of the associations between platelet count and hypertension nor to the associations between SNP (rs3782886) and hypertension), alcohol consumption (never-drinker, former drinker, current drinker [<23 g/week, 23-46 g/ week, $47-68 \mathrm{~g} /$ week, $\geq 69 \mathrm{~g} /$ week]), smoking status (never-smoker, former smoker, current smoker), HDLc $(\mathrm{mg} / \mathrm{dL})$, TG $(\mathrm{mg} / \mathrm{dL})$, HbA1C $(\%)$, and serum creatinine $(\mathrm{mg} / \mathrm{dL})$.

For the sensitivity analysis, we repeated our investigations with sex-specific models.

All statistical analyses were performed with the SAS system for Windows (version 9.4; SAS Inc., Cary, $\mathrm{NC}$ ). Values of $<0.05$ were regarded as being statistically significant.

\section{Results}

\section{Characteristics of study population in relation to platelet} levels

Characteristics of the study population in relation to platelet levels are shown in Table 1. The current smoker group showed positive associations with platelet levels while age and serum creatinine were inversely associated with platelet levels.

\section{Association between platelet levels and hypertension}

Table 2 shows ORs and 95\% CIs for hypertension in relation to platelet count. Independent of known cardiovascular risk factors, the high platelet level group showed significantly higher OR for hypertension compared with the reference group of non-high platelet levels (T1 and T2); the adjusted OR and 95\% CI for hypertension was $1.34(1.02,1.77)$.

Table 1 Characteristics of the study population in relation to platelet levels

\begin{tabular}{|c|c|c|c|c|}
\hline & \multicolumn{3}{|c|}{ Platelet levels } & \multirow[t]{2}{*}{$P$} \\
\hline & T1 (low) & $\mathrm{T} 2$ & T3 (high) & \\
\hline No. of participants & 332 & 327 & 329 & \\
\hline Age, years & $73.6 \pm 7.1$ & $72.4 \pm 7.3$ & $71.6 \pm 7.4$ & 0.003 \\
\hline Gender of men, \% & 37.0 & 37.6 & 37.4 & 0.989 \\
\hline Body mass index (BMI), $\mathrm{kg} / \mathrm{m}^{2}$ & $23.1 \pm 3.6$ & $23.3 \pm 3.1$ & $23.2 \pm 3.2$ & 0.776 \\
\hline Systolic blood pressure, mmHg & $139 \pm 18$ & $139 \pm 17$ & $141 \pm 19$ & 0.179 \\
\hline Diastolic blood pressure, $\mathrm{mmHg}$ & $80 \pm 11$ & $81 \pm 11$ & $82 \pm 11$ & 0.080 \\
\hline Current drinker, \% & 22.6 & 23.5 & 27.4 & 0.323 \\
\hline Current smoker, \% & 3.3 & 6.4 & 8.8 & 0.013 \\
\hline Serum triglycerides (TG), mg/dL & $93 \pm 54$ & $108 \pm 63$ & $106 \pm 53$ & 0.001 \\
\hline Serum HDL cholesterol (HDLc), mg/dL & $59 \pm 16$ & $60 \pm 18$ & $60 \pm 15$ & 0.565 \\
\hline Hemoglobin A1c (HbA1c), \% & $5.7 \pm 0.5$ & $5.6 \pm 0.4$ & $5.8 \pm 0.6$ & 0.002 \\
\hline Serum creatinine, mg/dL & $0.78 \pm 0.22$ & $0.75 \pm 0.19$ & $0.73 \pm 0.18$ & 0.003 \\
\hline Platelets, $\times 10^{4} / \mu \mathrm{L}$ & $16.6 \pm 2.7$ & $21.5 \pm 1.4$ & $27.7 \pm 5.1$ & $<0.001$ \\
\hline
\end{tabular}

Values: mean \pm standard deviation. Platelet levels for men are $<18.7 \times 10^{4} / \mu \mathrm{L}$ for $\mathrm{T} 1,18.7-21.9 \times 10^{4} / \mu \mathrm{L}$ for $\mathrm{T} 2$, and $\geq 22.0 \times 10^{4} / \mu \mathrm{L}$ for $\mathrm{T} 3$, for women are $<20.3 \times$ $10^{4} / \mu \mathrm{L}$ for $\mathrm{T} 1,20.3-24.1 \times 10^{4} / \mu \mathrm{L}$ for $\mathrm{T} 2$, and $\geq 24.2 \times 10^{4} / \mu \mathrm{L}$ for $\mathrm{T} 3$ 
Table 2 Odds ratios (ORs) and 95\% confidence intervals (Cls) for hypertension in relation to platelet levels

\begin{tabular}{|c|c|c|c|c|c|}
\hline & \multicolumn{3}{|c|}{ Platelet levels } & \multirow{2}{*}{$\begin{array}{l}P \text { for } \\
\text { trend }\end{array}$} & \multirow{2}{*}{$\begin{array}{l}1 \mathrm{SD} \text { increment } \\
\text { platelet }\end{array}$} \\
\hline & T1 (low) & $\mathrm{T} 2$ & T3 (high) & & \\
\hline No. at risk & 332 & 327 & 329 & & \\
\hline No. of cases (percentage) & $160(48.2)$ & $170(52.0)$ & $185(56.2)$ & & \\
\hline \multirow[t]{2}{*}{ Model 1} & 1.00 & $1.22(0.89,1.66)$ & $1.49(1.09,2.04)$ & 0.012 & $1.16(1.02,1.33)$ \\
\hline & 1.00 & & $1.35(1.03,1.77)$ & 0.029 & \\
\hline \multirow[t]{2}{*}{ Model 2} & 1.00 & $1.20(0.87,1.64)$ & $1.47(1.07,2.03)$ & 0.018 & $1.15(1.01,1.32)$ \\
\hline & 1.00 & & $1.34(1.02,1.77)$ & 0.036 & \\
\hline
\end{tabular}

Model 1 adjusted only for sex and age. Model 2 further adjusted for body mass index, alcohol consumption (never-drinker, former drinker, current drinker [<23 g/ week, 23-45 g/week, 46-68 g/week, $\geq 69 \mathrm{~g} /$ week]), smoking status (never-smoker, former smoker, current smoker), HDL cholesterol, triglycerides, HbA1C, and serum creatinine. Hypertension is defined as systolic blood pressure $\geq 140 \mathrm{mmHg}$ and/or diastolic blood pressure $\geq 90 \mathrm{mmHg}$. Platelet levels for men are $<18.7 \times$ $10^{4} / \mu \mathrm{L}$ for $\mathrm{T} 1,18.7-21.9 \times 10^{4} / \mu \mathrm{L}$ for $\mathrm{T} 2$, and $\geq 22.0 \times 10^{4} / \mu \mathrm{L}$ for T3, for women are $<20.3 \times 10^{4} / \mu \mathrm{L}$ for $\mathrm{T} 1,20.3-24.1 \times 10^{4} / \mu \mathrm{L}$ for $\mathrm{T} 2$, and $\geq 24.2 \times 10^{4} / \mu \mathrm{L}$ for $\mathrm{T} 3.1$ standard deviation (SD) increments of platelet are $6.23 \times 10^{4} / \mu \mathrm{L}$ for men and $5.26 \times 10^{4} / \mu \mathrm{L}$ for women

\section{Characteristics of the study population by genotype of SNPs (rs3782886)}

Characteristics of the study population by genotype of SNPs (rs3782886) are shown in Table 3. Of the 988 elderly Japanese participants, 609 were major homogeneous (A/ A), 332 were heterogeneous $(\mathrm{A} / \mathrm{G})$, and 47 were minor homogeneous $(\mathrm{G} / \mathrm{G})$. This SNP was in Hardy-Weinberg equilibrium. Current drinker was inversely significantly associated with minor allele frequency $(G)$ while platelet level showed a significantly positive association.

\section{Associations between rs3782886 genotype and high platelet levels}

Table 4 shows the associations between genotype and high platelet levels. For model 1 with major homogeneity (A/A) as the reference group, no significant association was observed for heterogeneity (A/G), while a significant association was observed for minor homogeneity (G/G). When we made further adjustment for other known cardiovascular risk factors, those associations with the reference group became slightly stronger and the statistical value became significant for heterogeneity.

\section{Associations between the rs3782886 genotype and short stature}

Table 5 shows the associations between genotype and short stature. With major homogeneity (A/A) as the reference group, no significant association was observed for heterogeneity $(\mathrm{A} / \mathrm{G})$, while a significant association was observed for minor homogeneity $(\mathrm{G} / \mathrm{G})$. However, a comparison of the two categories non-minor homogeneity and minor homogeneity showed a significant association.

\section{Associations between rs3782886 genotype and hypertension}

No significant associations between genotype and hypertension were observed (Table 6).

Table 3 Characteristics of the study population by genotype of rs3782886

\begin{tabular}{|c|c|c|c|c|}
\hline & \multicolumn{3}{|l|}{ rs3782886 } & \multirow[t]{2}{*}{$P$} \\
\hline & Major homo (A/A) & Hetero type (A/G) & Minor homo (G/G) & \\
\hline No. of participants & 609 & 332 & 47 & \\
\hline Age, years & $72.1 \pm 7.2$ & $73.2 \pm 7.4$ & $72.8 \pm 7.1$ & 0.089 \\
\hline Gender of men, \% & 36.3 & 40.1 & 31.9 & 0.382 \\
\hline Body mass index (BMI), kg/m² & $23.1 \pm 3.2$ & $23.4 \pm 3.5$ & $23.0 \pm 3.3$ & 0.274 \\
\hline Systolic blood pressure, mmHg & $140 \pm 18$ & $140 \pm 18$ & $139 \pm 19$ & 0.990 \\
\hline Diastolic blood pressure, $\mathrm{mmHg}$ & $82 \pm 11$ & $80 \pm 11$ & $81 \pm 11$ & 0.134 \\
\hline Current drinker, \% & 32.7 & 13.0 & 0.0 & $<0.001$ \\
\hline Current smoker, \% & 7.2 & 4.8 & 2.1 & 0.171 \\
\hline Serum triglycerides (TG), mg/dL & $102 \pm 60$ & $103 \pm 53$ & $100 \pm 39$ & 0.941 \\
\hline Serum HDL cholesterol (HDLc), mg/dL & $61 \pm 17$ & $58 \pm 15$ & $60 \pm 18$ & 0.066 \\
\hline Hemoglobin A1c (HbA1c), \% & $5.7 \pm 0.5$ & $5.7 \pm 0.5$ & $5.7 \pm 0.6$ & 0.722 \\
\hline Serum creatinine, mg/dL & $0.75 \pm 0.20$ & $0.77 \pm 0.19$ & $0.75 \pm 0.20$ & 0.149 \\
\hline Platelets, $\times 10^{4} / \mu \mathrm{L}$ & $21.5 \pm 4.9$ & $22.4 \pm 6.9$ & $23.2 \pm 4.9$ & 0.019 \\
\hline
\end{tabular}

Values: mean \pm standard deviation 
Table 4 Odds ratios (ORs) and 95\% confidence intervals (Cls) for high platelet in relation to rs3782886 genotype

\begin{tabular}{|c|c|c|c|c|}
\hline & \multicolumn{3}{|l|}{ rs3782886 } & \multirow{3}{*}{$\begin{array}{l}P \text { for } \\
\text { trend }\end{array}$} \\
\hline & \multicolumn{2}{|l|}{ Non-minor homo } & \multirow{2}{*}{$\begin{array}{l}\text { Minor homo } \\
(\mathrm{G} / \mathrm{G})\end{array}$} & \\
\hline & Major homo (A/A) & Hetero (A/G) & & \\
\hline No. at risk & 609 & 332 & 47 & \\
\hline No. of cases (percentage) & $186(30.5)$ & $119(35.8)$ & $24(51.1)$ & \\
\hline \multirow[t]{2}{*}{ Model 1} & 1.00 & $1.31(0.99,1.74)$ & $2.44(1.34,4.45)$ & 0.002 \\
\hline & 1.00 & & $2.21(1.22,3.99)$ & 0.009 \\
\hline \multirow[t]{2}{*}{ Model 2} & 1.00 & $1.49(1.10,2.01)$ & $2.86(1.52,5.37)$ & $<0.001$ \\
\hline & 1.00 & & $2.40(1.30,4.42)$ & 0.005 \\
\hline
\end{tabular}

Model 1 adjusted only for sex and age. Model 2 further adjusted for body mass index, systolic blood pressure, alcohol consumption (never-drinker, former drinker, current drinker [<23 g/week, 23-45 g/week, 46-68 g/week, $\geq 69 \mathrm{~g} /$ week]), smoking status (never-smoker, former smoker, current smoker), HDL cholesterol, triglycerides, $\mathrm{HbA} 1 \mathrm{C}$, and serum creatinine. The high platelet level is defined as the highest tertiles of platelets levels $\left(\geq 22.0 \times 10^{4} / \mu \mathrm{L}\right.$ for men and $\geq 24.2 \times 10^{4} / \mu \mathrm{L}$ for women)

The sensitivity analysis showed similar associations to those obtained for the main results.

\section{Discussion}

The major findings of the present study with elderly Japanese participants are that a high platelet level is positively associated with hypertension for elderly Japanese participants and that inflammation-related SNP (rs3782886) is significantly associated with a high platelet level and short stature.

Recently, platelets have been revealed to play a major role in inflammation, as well as to be important as an initial activator for the development of atherosclerotic lesions [38]. Even though development of atherosclerosis is only one aspect of endothelial repair, the association between hypertension and endothelial dysfunction (atherosclerosis) is bidirectional: hypertension induces increased arterial stiffness and vice versa [20-22]. Since our study presented here discovered a significant positive association between high platelet levels and hypertension, the former can be assumed to indicate a greater level of endothelial repair activity. In one of our previous studies, a high platelet count was found to be positively associated with hypertension in elderly men [18]. We also found that platelet levels are positively associated with carotid intima-media thickness (CIMT) in elderly hypertensive men $[18,19]$. Those findings also support our hypothesis that a high platelet count is likely to indicate a higher level of endothelial repair activity. In addition, SNP (rs3782886) is known to be located in the BRAP gene on chromosome 12q24 and that a higher expression of the BRAP minor allele is associated with an increased risk of atherosclerosis by heightening the degree of inflammation through activation of the NF- $k B$ protein $[15,39]$. Since activation of the NF- $-\mathrm{kB}$ pathway also could promote platelet activation protein [40], our finding that SNP (rs3782886) is significantly associated with high platelet levels is likely to indicate that the genetic factor might influence the level of endothelial repair activity.

Furthermore, short stature has been shown to constitute an inflammatory risk for elderly Japanese men as shown by a high white blood cell count [25]. Moreover, SNPs (rs3782886) were shown to be associated with short stature in a previous study by us [14]. SNPs (rs3782886) were also found to be significantly

Table 5 Odds ratios (ORs) and 95\% confidence intervals (Cls) for short stature in relation to rs3782886 genotype

\begin{tabular}{|c|c|c|c|c|}
\hline & \multicolumn{3}{|l|}{ rs3782886 } & \multirow{3}{*}{$\begin{array}{l}P \text { for } \\
\text { trend }\end{array}$} \\
\hline & \multicolumn{2}{|l|}{ Non-minor homo } & \multirow{2}{*}{$\begin{array}{l}\text { Minor homo } \\
(\mathrm{G} / \mathrm{G})\end{array}$} & \\
\hline & Major homo (A/A) & Hetero (A/G) & & \\
\hline No. at risk & 609 & 332 & 47 & \\
\hline No. of cases (percentage) & $132(21.7)$ & $94(28.3)$ & $19(40.4)$ & \\
\hline \multirow[t]{2}{*}{ Model 1} & 1.00 & $1.32(0.96,1.83)$ & $2.55(1.33,4.89)$ & 0.004 \\
\hline & 1.00 & & $2.30(1.21,4.36)$ & 0.011 \\
\hline \multirow[t]{2}{*}{ Model 2} & 1.00 & $1.33(0.94,1.87)$ & $2.51(1.29,4.89)$ & 0.006 \\
\hline & 1.00 & & $2.21(1.16,4.21)$ & 0.016 \\
\hline
\end{tabular}

Model 1 adjusted only for sex and age. Model 2 further adjusted for body mass index, systolic blood pressure, alcohol consumption (never-drinker, former drinker, current drinker [ $<23 \mathrm{~g} /$ week, 23-45 g/week, 46-68 g/week, $\geq 69 \mathrm{~g} /$ week]), smoking status (never-smoker, former smoker, current smoker), HDL cholesterol, triglycerides, $\mathrm{HbA1C}$, and serum creatinine. Short stature is defined as a height level at or under the 25 th percentile of the study population $(<158.4 \mathrm{~cm}$ for men and 
Table 6 Odds ratios (ORs) and 95\% confidence intervals (Cls) for hypertension in relation to rs3782886 genotype

\begin{tabular}{|c|c|c|c|c|}
\hline & \multicolumn{3}{|l|}{ rs3782886 } & \multirow{3}{*}{$\begin{array}{l}P \text { for } \\
\text { trend }\end{array}$} \\
\hline & \multicolumn{2}{|l|}{ Non-minor homo } & \multirow{2}{*}{$\begin{array}{l}\text { Minor homo } \\
(\mathrm{G} / \mathrm{G})\end{array}$} & \\
\hline & Major homo (A/A) & Hetero (A/G) & & \\
\hline No. at risk & 609 & 332 & 47 & \\
\hline No. of cases (percentage) & $320(52.5)$ & $170(51.2)$ & $25(53.2)$ & \\
\hline \multirow[t]{2}{*}{ Model 1} & 1.00 & $0.91(0.70,1.20)$ & $1.00(0.55,1.82)$ & 0.652 \\
\hline & 1.00 & & $1.03(0.57,1.87)$ & 0.912 \\
\hline \multirow[t]{2}{*}{ Model 2} & 1.00 & $0.93(0.70,1.23)$ & $1.05(0.57,1.93)$ & 0.324 \\
\hline & 1.00 & & $1.08(0.60,1.98)$ & 0.791 \\
\hline
\end{tabular}

Model 1 adjusted only for sex and age. Model 2 further adjusted for body mass index, alcohol consumption (never-drinker, former drinker, current drinker [<23 g/ week, 23-45 g/week, 46-68 g/week, $\geq 69$ g/week]), smoking status (never-smoker, former smoker, current smoker), HDL cholesterol, triglycerides, HbA1C, and serum creatinine. Hypertension is defined as systolic blood pressure $\geq 140 \mathrm{mmHg}$ and/or diastolic blood pressure $\geq 90 \mathrm{mmHg}$

associated with a high platelet count and short stature in the current study, indicating that the genetic factor may at least partly influence the risk of inflammatory changes which induce endothelial repair in participants with short stature. Another study by us of elderly men also supports the notion of this mechanism. In this study, we showed that platelet level is positively associated with CIMT and circulating endothelial progenitor cells (CD34-positive cells) while height is inversely associated with platelet count for participants with high hemoglobin levels [23].

The inverse association between height and hypertension which is reported in a Chinese study [2] is probably due to a reduced anti-oxidative stress capacity $[20,21$, 41] since short stature is associated with lower hematopoiesis activity $[9,10]$ and higher risk of anemia [11]. Lower endothelial repair capacity which is a characteristic of short stature $[23,30]$ also might induce hypertension because of its reduced ability to compensate for blockage of the blood flow. Moreover, hypertension is a well-known major risk factor for stroke in Japanese [1] who are known to be characterized by short stature and low BMI. Since we reported in a previous study that height was inversely associated with the incidence of stroke only in participants with low BMI $\left(<23 \mathrm{~kg} / \mathrm{m}^{2}\right)$ [4], and that carotid atherosclerosis was inversely associated with height only in participants with high BMI $(\geq$ $25 \mathrm{~kg} / \mathrm{m}^{2}$ ) [3], carotid atherosclerosis alone could not explain the risk of stroke for Japanese with short stature. In fact, reduced capability for endothelial repair $[23,30]$ and hypertension [2] characteristic of short stature might perform an important role in the incidence of stroke for participants with short stature. Since BRAP is reportedly associated with atherosclerosis [15] but not associated with stroke [16] and SNPs (rs3782886) are associated with short stature [14], SNP (rs3782886) might perform an import function for the prevention of stroke for participants with short stature by stimulating endothelial repair. In the present study, even though SNP (rs3782886) was found to be associated with a high platelet count, which is related to hypertension, no significant association between SNP (rs3782886) and hypertension was observed, which partly supports the aforementioned mechanisms because adequate endothelial maintenance was performed predominantly for normal body weight participants. To clarify those mechanisms, further study is needed with a larger population which makes it possible to perform a BMI status-specific analysis of the relationship between SNP (rs3782886) and hypertension.

From the anthropological point of view, an extensive presence of SNP (rs3782886) should have some beneficial effects on life activities rather than disadvantages. Even though SNP (rs3782886) is reportedly associated with myocardial infarction [13], the findings presented here indicate that the beneficial effect of SNP (rs3782886) is a high endothelial repair activity among participants with short stature whose endothelial repair activity is low $[9,10,23]$.

The present findings are efficient for clarifying the mechanism underlying the association between height and endothelial repair as they indicate that genetic factors could at least partly influence this association. In addition, the present findings also clarify the reason why the extensive presence of inflammatory disadvantage-associated SNP (rs3782886) $[13,15]$ could be established among the general Japanese population.

Possible limitations of this study warrant consideration. First, because creatinine clearance data were not available and estimated glomerular filtration rate (GFR) is not an effective tool for evaluating kidney function for a comparison of associations with various body heights $[3,4,9,10,25,42]$, we could not perform an analysis adjusted for accurate renal function. However, our study showed that associations, such as between high platelet and hypertension, SNPs (rs3782886) and high platelet level, and SNPs (rs3782886) and short stature, remained significant even after adjustment for serum creatinine. Second, because this was a cross-sectional study, causal 
relationships were not able to be established. Furthermore, because our study used elderly Japanese who participated in a general health check-up, selection bias arising from this kind of study is unavoidable.

\section{Conclusion}

In conclusion, there is a significant and positive association between high platelet count and hypertension, and SNPs (rs3782886) were shown to be associated with high platelet count and short stature. These results partly explain how a genetic factor can influence the impact of height on endothelial repair.

\begin{abstract}
Abbreviations
ANOVA: Analysis of variance; BMI: Body mass index; BRAP: BRCA1-related associated protein; Cl: Confidence interval; CIMT: Carotid intima-media thickness; GFR: Glomerular filtration rate; HbA1c: Hemoglobin A1c; HDLc: HDL cholesterol; OR: Odds ratio; SD: Standard deviation; SNP: Single-nucleotide polymorphism; TG: Triglycerides
\end{abstract}

\section{Acknowledgements}

We are grateful to staff from Goto City Hall for their outstanding support.

\section{Funding}

This study was supported by Grants-in-Aids for Scientific Research from the Japan Society for the Promotion of Sciences (No.18 K06448, No.17H03740).

\section{Availability of data and materials}

The datasets generated during and/or analyzed during the current study are not publicly available due to ethical consideration but are available from the corresponding author on reasonable request.

\section{Authors' contributions}

YS designed the study and performed the statistical analyses, interpreted the data, and drafted the manuscript or revised it. YS, HY, YN, JK, MN, SF, MT, SYK, and KA assisted with the design of the study, were involved in the data collection, and checked the manuscript. HY, S-YK, and TM participated in the study concept and checked the manuscript. TM was the general coordinator and also designed the study. All authors read and approved the final manuscript.

\section{Ethics approval and consent to participate}

All procedures performed in studies involving human participants were in accordance with the ethical standards of the institution research committee and with the 1964 Helsinki declaration and its later amendments for comparable ethical standards. The Ethics Committee for Human Use of Nagasaki University obtained ethical approval. This study was approved by the Ethics Committee of Nagasaki University Graduate School of Biomedical Sciences (project registration number 14051404). Written consent forms were available in Japanese to ensure comprehensive understanding of the study objectives, and informed consent was provided by the participants.

\section{Consent for publication}

Not applicable

\section{Competing interests}

The authors declare that they have no competing interests.

\section{Publisher's Note}

Springer Nature remains neutral with regard to jurisdictional claims in published maps and institutional affiliations.

\section{Author details}

'Department of Community Medicine, Nagasaki University Graduate School of Biomedical Sciences, Nagasaki-shi, Sakamoto 1-12-4, Nagasaki 852-8523, Japan. ${ }^{2}$ Department of Cardiovascular Disease Prevention, Osaka Center for
Cancer and Cardiovascular Disease Prevention, Osaka, Japan. ${ }^{3}$ Department of General Medicine, Nagasaki University Hospital, Nagasaki, Japan. ${ }^{4}$ Department of Island and Community Medicine, Nagasaki University Graduate School of Biomedical Sciences, Nagasaki, Japan. ${ }^{5}$ Department of Immunology and Rheumatology, Nagasaki University Graduate School of Biomedical Sciences, Nagasaki, Japan. ${ }^{6}$ Department of Public Health, Nagasaki University Graduate School of Biomedical Sciences, Nagasaki, Japan.

Received: 3 September 2018 Accepted: 9 April 2019

Published online: 01 May 2019

\section{References}

1. Kitamura A, Yamagishi K, Imano H, Kiyama M, Cui R, Ohira T, et al; CIRCS Investigators. Impact of hypertension and subclinical organ damage on the incidence of cardiovascular disease among Japanese residents at the population and individual levels - The Circulatory Risk in Communities Study (CIRCS). Circ J. 2017;81(7):1022-8.

2. Song L, Shen L, Li H, Liu B, Zheng X, Liang Y, et al. Height and prevalence of hypertension in a middle-aged and older Chinese population. Sci Rep. 2016;6:39480.

3. Shimizu Y, Nakazato M, Sekita T, Kadota K, Arima K, Yamasaki H, et al. Relationship between adult height and body weight and risk of carotid atherosclerosis assessed in terms of carotid intima-media thickness: the Nagasaki Islands study. J Physiol Anthropol. 2013;32:19.

4. Shimizu Y, Imano H, Ohira T, Kitamura A, Kiyama M, Okada T, et al; CIRCS Investigators. Adult height and body mass index in relation to risk of total stroke and its subtypes: the circulatory risk in communities study. I Stroke Cerebrovasc Dis. 2014;23(4):667-74.

5. Shi Q, Rafii S, Wu MH, Wijelath ES, Yu C, Ishida A, et al. Evidence for circulating bone marrow-derived endothelial cells. Blood. 1998;92(2):362-7.

6. Shimizu Y, Kadota K, Nakazato M, Noguchi Y, Koyamatsu J, Yamanashi H, et al. Hemoglobin as a possible biochemical index of hypertension-induced vascular damage. J Physiol Anthropol. 2016;35:4.

7. Shimizu Y, Nakazato M, Sekita T, Kadota K, Yamasaki H, Takamura N, et al. Association between hemoglobin levels and arterial stiffness for general Japanese population in relation to body mass index status: the Nagasaki Islands study. Geriatr Gerontol Int. 2014;14(4):811-8.

8. Shimizu Y, Sato S, Koyamatsu J, Yamanashi H, Nagayoshi M, Kadota K, et al. Possible mechanism underlying the association between higher hemoglobin level and hypertension in older Japanese men. Geriatr Gerontol Int. 2017;17(12):2586-92.

9. Shimizu Y, Sato S, Koyamatsu J, Yamanashi H, Nagayoshi M, Kadota K, et al. Height indicates hematopoietic capacity in elderly Japanese men. Aging (Albany NY). 2016;8(10):2407-13.

10. Shimizu Y, Yamanashi H, Noguchi Y, Koyamatsu J, Nagayosi M, Kiyoura $K$, et al. Association between height and circulating CD34-posistive cells taken into account for the influence of enhanced production among elderly Japanese men: a cross-sectional study. Aging (Albany NY). 2019; 11(2):663-72.

11. Shimizu Y, Nakazato M, Sekita T, Kadota K, Miura Y, Arima K, et al. Height and drinking status in relation to risk of anemia in rural adult healthy Japanese men: the Nagasaki Islands study. Aging Male. 2015;18(2):100-5.

12. Shimizu Y, Nakazato M, Sekita T, Kadota K, Arima K, Yamasaki H, et al. Association between the hemoglobin levels and hypertension in relation to the BMI status in a rural Japanese population: the Nagasaki Islands Study. Intern Med. 2014;53(5):435-40.

13. Ozaki K, Sato H, Inoue K, Tsunoda T, Sakata Y, Mizuno H, et al. SNPs in BRAP associated with risk of myocardial infarction in Asian populations. Nat Genet. 2009:41(3):329-33.

14. Shimizu Y, Sato S, Noguchi Y, Koyamatsu J, Yamanashi H, Higashi M, et al. Impact of single nucleotide polymorphism on short stature and reduced tongue pressure among community-dwelling elderly Japanese participants: a cross-sectional study. Environ Health Prev Med. 2017;22(1):62.

15. Liao YC, Wang YS, Guo YC, Ozaki K, Tanaka T, Lin HF, et al. BRAP activates inflammatory cascades and increases the risk for carotid atherosclerosis. Mol Med. 2011;17(9-10):1065-74.

16. Liao YC, Lin HF, Guo YC, Chen CH, Huang ZZ, Juo SH, et al. Lack of association between a functional variant of the BRCA-1 related associated protein (BRAP) gene and ischemic stroke. BMC Med Genet. 2013;14:17.

17. Stellos K, Langer H, Daub K, Schoenberger T, Gauss A, Geisler T, et al. Platelet-derived stromal cell-derived factor-1 regulates adhesion and 
promotes differentiation of human CD34+ cells to endothelial progenitor cells. Circulation. 2008;117(2):206-15.

18. Shimizu Y, Sato S, Koyamatsu J, Yamanashi H, Nagayoshi M, Kadota K, et al. Platelets and circulating CD34-positive cells as an indicator of the activity of the vicious cycle between hypertension and endothelial dysfunction in elderly Japanese men. Atherosclerosis. 2017;259:26-31.

19. Shimizu Y, Sato S, Koyamatsu J, Yamanashi H, Nagayoshi M, Kadota K, et al. Platelets as an indicator of vascular repair in elderly Japanese men. Oncotarget. 2016;7(29):44919-26

20. Dohi Y. Hypertension and oxidative stress. Nagoya Med J. 2010;51(3):153-8. [Article in Japanese].

21. Higashi Y, Sueda T, Yoshizumi M. Role of angiotensin II-related oxidative stress and nitric oxide in endothelial function in hypertension. J Jpn Coll Angiol. 2003;43:47-52 [Article in Japanese].

22. Nakamura S, Moriguchi A, Morishita R, Aoki M, Yo Y, Hayahsi S, et al. A novel vascular modulator, hepatocyte growth factor (HGF), as a potential index of the severity of hypertension. Biochem Biophys Res Commun. 1998;242(1):238-43.

23. Shimizu Y, Sato S, Koyamatsu J, Yamanashi H, Nagayoshi M, Kadota K, et al. Possible mechanism underlying the association between height and vascular remodeling in elderly Japanese men. Oncotarget. 2018; 9(8):7749-57.

24. National Institute of Population and Social Security Research [Home page on the Internet]. Available from: http:/www.ipss.go.jp/pp-shicyoson/j/ shicyoson13/3kekka/Municipalities.asp. [Cited 14 April 2019].

25. Shimizu Y, Yoshimine H, Nagayoshi M, Kadota K, Takahashi K, Izumino K, et al. Short stature is an inflammatory disadvantage among middle-aged Japanese men. Environ Health Prev Med. 2016;21(5):361-7.

26. Kawada T. Relationships between the smoking status and plasma fibrinogen, white blood cell count and serum C-reactive protein in Japanese workers. Diabetes Metab Syndr. 2015;9(3):180-2.

27. Shimizu Y, Sato S, Koyamatsu J, Yamanashi H, Nagayoshi M, Kawashiri SY, et al. Hepatocyte growth factor and carotid intima-media thickness in relation to circulating CD34-positive cell levels. Environ Health Prev Med. 2018;23(1):16.

28. Shimizu Y, Sato S, Koyamatsu J, Yamanashi H, Nagayoshi M, Kadota K, et al. Association between high-density lipoprotein-cholesterol and hypertension in relation to circulating CD34-positive cell levels. J Physiol Anthropol. 2017; 36(1):26.

29. Shimizu Y, Sato S, Noguchi Y, Koyamatsu J, Yamanashi H, Nagayoshi M, et al. Triglycerides and blood pressure in relation to circulating CD34-positive cell levels among community-dwelling elderly Japanese men: a crosssectional study. Environ Health Prev Med. 2017;22(1):77.

30. Shimizu Y, Sato S, Koyamatsu J, Yamanashi H, Nagayoshi M, Kadota K, et al. Height is an indicator of vascular maintenance capacity in older men. Geriatr Gerontol Int. 2017;17(10):1729-36.

31. Nelson CP, Hamby SE, Saleheen D, Hopewell JC, Zeng L, Assimes TL, et al. Genetically determined height and coronary artery disease. N Engl J Med. 2015;372(17):1608-18.

32. Shimizu Y, Nakazato M, Sato S, Koyamatsu J, Yamanashi H, Nagayoshi $\mathrm{M}$, et al. Association between hemoglobin A1c and carotid atherosclerosis in rural community-dwelling elderly Japanese men. $J$ Physiol Anthropol. 2015;34:16.

33. Shimizu Y, Nakazato M, Sekita T, Kadota K, Yamasaki H, Takamura N, et al. Association of arterial stiffness and diabetes with triglycerides-to-HDL cholesterol ratio for Japanese men: the Nagasaki Islands Study. Atherosclerosis. 2013:228(2):491-5.

34. Kubo $\mathrm{Y}$, Imaizumi $\mathrm{T}$, Ando $\mathrm{M}$, Nakatochi $\mathrm{M}$, Yasuda $\mathrm{Y}$, Honda $\mathrm{H}$, et al. Association between kidney function and genetic polymorphisms in atherosclerotic and chronic kidney diseases: a cross-sectional study in Japanese male workers. PLoS One. 2017:12(10):e0185476.

35. Shimizu Y, Sato S, Koyamatsu J, Yamanashi H, Nagayoshi M, Kadota K, et al. Circulating CD34-positive cells, glomerular filtration rate and triglycerides in relation to hypertension. Atherosclerosis. 2015;243(1):71-6.

36. Shimizu Y, Sato S, Koyamatsu J, Yamanashi H, Nagayoshi M, Kadota K, et al. Associations between renal impairment and anemia in older, rural Japanese men: the Nagasaki Island study. J Physiol Anthropol. 2014;33:7.

37. Shimizu Y, Maeda K, Imano H, Ohira T, Kitamura A, Kiyama M, et al. Chronic kidney disease and drinking status in relation to risks of stroke and its subtypes: the Circulatory Risk in Communities Study (CIRCS). Stroke. 2011; 42(9):2531-7.

38. Lindemann S, Krämer B, Seizer P, Gawaz M. Platelets, inflammation and atherosclerosis. J Thromb Haemost. 2007;5:203-11.
39. Karin M, Delhase M. The I kappa B kinase (IKK) and NF-kappa B: key elements of proinflammatory signalling. Semin Immunol. 2000;12(1):85-98.

40. Schattner M. Role of NF-KB pathway on platelet activation. Circ Res. 2013; 113(9):e92.

41. Ahmad KA, Yuan Yuan D, Nawaz W, Ze H, Zhuo CX, Talal B, et al. Antioxidant therapy for management of oxidative stress induced hypertension. Free Radic Res. 2017;51(4):428-38.

42. Shimizu Y, Yoshimine H, Nagayoshi M, Kadota K, Takahashi K, Izumino K, et al. Height correlates with dyslipidemia in non-overweight middle-aged Japanese men. J Physiol Anthropol. 2016;35(1):29.

\section{Ready to submit your research? Choose BMC and benefit from:}

- fast, convenient online submission

- thorough peer review by experienced researchers in your field

- rapid publication on acceptance

- support for research data, including large and complex data types

- gold Open Access which fosters wider collaboration and increased citations

- maximum visibility for your research: over $100 \mathrm{M}$ website views per year

At BMC, research is always in progress.

Learn more biomedcentral.com/submissions 